\title{
Microstructure, corrosion and tribological and antibacterial properties of Ti-Cu coated stainless steel
}

\author{
Xiaomin Jin ${ }^{\mathrm{a}}$, Lizhen Gao ${ }^{\mathrm{a}}$, Erqiang Liu ${ }^{\mathrm{b}}$, Feifei Yu ${ }^{\mathrm{b}}$, Xuefeng Shu ${ }^{\mathrm{b}}$, Hefeng Wang ${ }^{\mathrm{c}}$ \\ ${ }^{\text {a }}$ College of Environmental Science and Engineering, Taiyuan University of Technology, \\ Taiyuan 030024, China \\ ${ }^{\mathrm{b}}$ Institute of Applied Mechanics and Biomedical Engineering, Taiyuan University of \\ Technology, Taiyuan 030024, China \\ ${ }^{c}$ College of Mechanics, Taiyuan University of Technology, Taiyuan 030024, China \\ E-mail: gaolizhentyut@163.com, Tel: +86-0351-6010540
}

\begin{abstract}
A Ti-Cu coated layer on $316 \mathrm{~L}$ stainless steel (SS) was obtained by using the Closed Field Unbalanced Magnetron Sputtering (CFUBMS) system to improve antibacterial activity, corrosion and tribological properties. The microstructure and phase constituents of Ti-Cu coated layer were characterized by using X-ray diffraction (XRD), scanning electron microscopy (SEM) and glow discharge optical emission spectrometry (GDOES). The corrosion and tribological properties of a stainless steel substrate, SS316L, when coated with Ti-Cu were investigated in a simulated body fluid (SBF) environment. The viability of bacteria attached to the antibacterial surface was tested using the spread plate method. The results indicate that the Ti-Cu coated SS316L could achieve a higher corrosion polarization resistance and a more stable corrosion potential in an SBF environment than the uncoated SS316L substrate. The desirable corrosion protection performance of $\mathrm{Ti}-\mathrm{Cu}$ may be attributable to the
\end{abstract}


formation of a Ti-O passive layer on the coating surface, protecting the coating from further corrosion. The Ti-Cu coated SS316L also exhibited excellent wear resistance and chemical stability during the sliding tests against $\mathrm{Si}_{3} \mathrm{~N}_{4}$ balls in SBF environment. Moreover, the Ti-Cu coatings exhibited excellent antibacterial abilities, where an effective reduction of $99.9 \%$ of Escherichiacoli (E.coli) within 12 h was achieved by contact with the modified surface, which was attributed to the release of copper ions when the Ti-Cu coatings are in contact with bacterial solution.

Keywords: Magnetron sputtering; Corrosion; Tribological property; Antibacterial; Ti- $\mathrm{Cu}$ coated layer; Stainless steel

\section{Introduction}

In general, a solid solution austenitic phase $(\gamma)$ with high chromium content (12\%-20\%) is responsible for the excellent corrosion performance of austenitic alloys. This allows for the use of these alloys in biomedical, public and food industries [1-4]. However, they do not possess antibacterial properties. Inflammation and infection, which are usually caused by adherence and colonization of bacteria on biomaterials, can result in patients developing serious complications [5], making it crucial to improve the antibacterial properties of stainless steel (SS). Promising methods that have been described recently are the deposition of a protective ceramic coating on the metal surface and, for medical applications, applying a coating of silver or copper as these have strong antibacterial properties [6-10]. On the other hand, surface coatings on metals or alloys usually affect their anticorrosion properties $[2,5$, 11-14]. Creating a coating that provides a strong antibacterial effect together with 
good wear and corrosion resistance is challenging. Therefore, new ways to enhance the antibacterial properties of SS surfaces that do not have a negative impact on its base performance are required. Several metal ions $\left(\mathrm{Cu}^{2+}, \mathrm{Ag}^{+}\right.$and $\left.\mathrm{Zn}^{+}\right)$are described as antibacterial agents that could be used for metal-ion based deposition on implant surfaces [15-17]. In particular, copper represents a more promising metal ion for deposition applications because of its lower toxicity and higher cytocompatibility [18]. For these reasons copper was employed as the antibacterial agent in our study. In addition, the decrease in the corrosion resistance of SS is caused by heavy precipitations of chromium carbide and chromium nitride on the grain boundaries, which are surrounded by chromium-depleted zones [19]. The general method to prevent intergranular corrosion is to reduce the content of carbon and nitrogen and to add a stabilizer such as $\mathrm{Ti}$ or $\mathrm{Nb}[20,21]$. Ti in particular has been considered an effective alloying element to improve the corrosion resistance of SS [22]. Additionally, Ti is also used to increase adhesion to SS surfaces and to increase the hardness of the Ti- $\mathrm{Cu}$ coatings.

In this study, $\mathrm{Cu}$ and $\mathrm{Ti}$ were successfully introduced into SS surfaces to improve their antibacterial activity and corrosion resistance using a closed field unbalanced magnetron sputtering system. The advantage of this technique is that unbalanced magnetron sputtering of the target field can improved the plasma density of the deposition area, which can significantly improve the quality of the coatings. The objective of the study was to characterize the chemical composition, microstructure, corrosion, tribological and antibacterial properties of Ti-Cu coated SS. 


\section{Experimental}

\subsection{Material and methods}

Coatings were produced on AISI316L SS plates. AISI316L SS samples $(\Phi 20 \mathrm{~mm} \times 5 \mathrm{~mm})$ were ground with No. $80-1500$ emery papers, and then ultrasonically cleaned in acetone.

Coatings were deposited using CFUMSIP equipment (Teer Coatings Ltd, UDP 550 ) with two $\mathrm{Cu}$ targets and two Ti targets (purity grade $99.99 \%$ ) of $145 \times 345 \times 8 \mathrm{~mm}$ in size. The distance of substrates and targets was fixed at $120 \mathrm{~mm}$. Substrates were fixed on the jig with three-axis rotation at a speed of $4 \mathrm{rpm}$. Argon gas with $99.999 \%$ purity was used as the sputtering medium. All the samples were bombarded by $\mathrm{Ar}^{+}$ ion for $30 \mathrm{~min}$ before deposition. The deposition pressure of the Ti-Cu coatings was $8.4 \times 10^{-2} \mathrm{~Pa}$, the discharge current for the sputtering of Ti was $I_{\mathrm{m}-\mathrm{Ti}}=400 \mathrm{~mA}$ and the discharge current for the sputtering of $\mathrm{Cu}$ was $I_{\mathrm{m}-\mathrm{Cu}}=100 \mathrm{~mA}$. A negative bias voltage $\left(V_{b}\right)$ of $-60 \mathrm{~V}$ was applied to substrates. The deposition time of the Ti-Cu coatings was $1.5 \mathrm{~h}$. The total thickness of the coatings was approximately $1.5 \mu \mathrm{m}$.

\subsection{Characterizations}

The surface morphologies and compositions of samples were observed using scanning electron microscopy (SEM, JSM-6360LV, VEGA $\$ TESCAN) with an energy dispersive spectrometer (EDS). The chemical composition of the alloyed layer was examined by glow discharge optical emission spectrometry (GDOES, GDA-750A Spectruma Analytik GmbH, Germany) in DC mode using the universal sample unit at $1000 \mathrm{~V}$ and constant pressure $(\sim 10 \mathrm{~mA})$. The crystalline phases were 
identified using a Rigaku DyMax 2500 X-ray diffraction spectrometer of $\mathrm{CuK} \alpha$ $(1.54 \AA)$ radiations in $\theta-2 \theta$ geometry at a scan speed of $1 \%$ min.

\subsection{Antimicrobial test}

The antibacterial activity of Ti-Cu coatings was studied against the Gram-negative Escherichia coli (E. coli). The broth for culturing the bacteria was made by dissolving $5.0 \mathrm{~g}$ flesh extract, $5.0 \mathrm{~g} \mathrm{NaCl}$ and $10.0 \mathrm{~g}$ peptone into $1000 \mathrm{ml}$ of distilled water with the $\mathrm{pH}$ adjusted to 7.0-7.2. The bacteria were cultured in a shaking incubator $\left(110 \mathrm{r} / \mathrm{min}, 37^{\circ} \mathrm{C}\right)$ over night. Before the microbiological experiment, all glassware and Ti-Cu coated SS samples were sterilized by autoclaving at $120{ }^{\circ} \mathrm{C}$ for $30 \mathrm{~min}$. For the antibacterial test, each sample was placed into a sterilized Petri dish. Then $0.1 \mathrm{ml}$ bacteria culture with a concentration of $10^{5} \mathrm{CFU} / \mathrm{ml}$ was dripped onto the surfaces of the samples. For experiments under visible light, a $150 \mathrm{~W}$ tungsten lamp equipped with an optical cutoff filter $(\lambda>420 \mathrm{~nm})$ was used as the light source. The bacteria on the sample surface were incubated for $6 \mathrm{~h}$ at $37^{\circ} \mathrm{C}$. After the incubation, the bacteria were washed off the SS surface with $0.9 \mathrm{ml}$ of phosphate buffer solution. Then $0.1 \mathrm{ml}$ of each bacteria suspension was spread on a nutrient agar plate and incubated for $24 \mathrm{~h}$ at $37{ }^{\circ} \mathrm{C}$ before counting the surviving bacterial colonies. The percentage reduction was calculated according to the equation 1

Reduction $\%=\left[\frac{\lambda_{0}-\lambda_{t}}{\lambda_{0}}\right] \times 100 \%$

Where $\lambda_{t}$ is the number of viable bacteria for the treated sample after a designated contact time and $\lambda_{0}$ is the number of viable bacteria for the untreated sample. In 
addition, every test was repeated three times for each material.

\subsection{Corrosion tests}

The corrosion properties of the uncoated and coated samples were evaluated by means of potentiodynamic polarization curves and electrochemical impedance spectroscopy (EIS). Freshly prepared Hank's solution was used for each experiment using commercial Hanks’ Balanced Salt (Sigma-Aldrich ${ }^{\circledR}$ ) as suggested, with the $\mathrm{pH}$ adjusted to be at 7.4. The chemical composition of the Hanks' solution is listed in Table 1. Electrochemical experiments were carried out using an electrochemical measurement system (PARSTAT-2273). The corrosion cell, which contained $1000 \mathrm{ml}$ of electrolyte, was combined with a typical three-electrode configuration. The saturated calomel electrode (SCE) was used as reference electrode and the counter electrode (CE) was a platinum plate. The uncoated and coated samples were employed as working electrodes (WE) with a naked geometric area of $1 \mathrm{~cm}^{2}$ respectively. All the electrolytes were set at $37^{\circ} \mathrm{C}$ to better simulate the human body fluid environment and the samples were immersed for 6 days.

Before EIS test, a stable open circuit potential (OCP) was achieved in order to guarantee sample stability in the electrolyte and a sinusoidal ac perturbation of $10 \mathrm{mV}$ vs OCP amplitude was applied to the electrode over the frequency range $0.1 \mathrm{~Hz}-100$ $\mathrm{kHz}$.

Potentiodynamic tests were performed on samples after one hour of immersion to achieve a stable OCP potential using a scanning rate of $0.1 \mathrm{mV} / \mathrm{s}$ from $-1000 \mathrm{mV}$ vs. OCP to $+1000 \mathrm{mV}$ vs. OCP. The surface morphology of the pitted area after the 
polarization test was studied by SEM. In addition, every test was repeated three times for each material.

\subsection{Tribological tests}

The tribological behavior of the coatings was characterized by a pin-on-disc tribometer against $\mathrm{Si}_{3} \mathrm{~N}_{4}$ balls as pins ( $5 \mathrm{~mm}$ in diameter) under boundary lubricated conditions with Hanks' solution. Fig. 1 shows the schematic diagram of sliding friction and wear testing apparatus. The sliding speed of the specimen relative to the ball was $5 \times 10^{-2} \mathrm{~m} / \mathrm{s}$, the sliding distance was $200 \mathrm{~m}$, and the normal load was $7.6 \mathrm{~N}$. The coefficient of friction of the sliding couple was recorded continuously during the test using a computerized data acquisition system. The morphologies of wear scars were observed using SEM with EDS.

\section{Results and discussions}

\subsection{Structure and element distributions}

The XRD patterns of Ti-Cu deposited films (Fig. 2) do not show any reflections of metallic hcp-Ti and fcc-Cu. The phase structures of Ti-Cu coated SS were mainly composed of $\mathrm{Cu}_{4} \mathrm{Ti}_{3}, \mathrm{Cu}_{0.81} \mathrm{Ni}_{0.19}, \mathrm{TiNi}_{0.8} \mathrm{Cu}_{0.2}$ and $\gamma$-Fe. New phases of $\mathrm{Cu}_{4} \mathrm{Ti}_{3}$, $\mathrm{Cu}_{0.81} \mathrm{Ni}_{0.19}$ and $\mathrm{TiNi}_{0.8} \mathrm{Cu}_{0.2}$ were synthesized after depositing. The appearance of the $\mathrm{TiNi}_{0.8} \mathrm{Cu}_{0.2}$ phase and $\mathrm{Cu}_{0.81} \mathrm{Ni}_{0.19}$ phase are in agreement with previous research [23]. They reported that the presence of unbound $\mathrm{Ti}, \mathrm{TiNi}_{0.8} \mathrm{Cu}_{0.2}, \mathrm{Cu}_{0.81} \mathrm{Ni}_{0.19}, \mathrm{Cu}_{2} \mathrm{Ti}_{4} \mathrm{O}$ and $\mathrm{Ti}_{2} \mathrm{Cu}$ can be found in XRD patterns of $\mathrm{Cu}-\mathrm{Ni}$ alloyed titanium. The presence of the $\mathrm{TiNi}_{0.8} \mathrm{Cu}_{0.2}$ and $\mathrm{Cu}_{0.81} \mathrm{Ni}_{0.19}$ phases was suggested to arise from the different interactions of sputtered metal particles with the substrate surface. However, Stranak 
et al. [9] reported that the Ti-Cu films prepared in dc-MS and dual-MS mode show only fcc- $\mathrm{Cu}$ reflections. This indicates that the amount of $\mathrm{Ti}$ is probably higher in Ti-Cu coated SS obtained by using the CFUBMS system than the direct current magnetron sputtering and dual magnetron sputtering systems.

The maximum thickness of the Ti-Cu coating obtained in present study is approximately $1.5 \mu \mathrm{m}$ (Fig. 3). The concentration of $\mathrm{Ti}$ and $\mathrm{Cu}$ gradually decreases from the surface to interior, which may significantly improve the bonding strength between the Ti-Cu coating and SS substrate. In addition, $\mathrm{SS}$ components ( $\mathrm{Fe}, \mathrm{Cr}$ and Ni) can also be observed at a short distance $(\sim 0.2 \mu \mathrm{m})$ inside the Ti-Cu coating as can be seen from the concentration profiles of these elements (Fig. 3). This phenomenon is likely due to the substrate signal as well as the signal from the layer that was also detected together by GDOES.

\subsection{Morphology of the coatings}

Fig. 4 shows the top-view of the SEM micrograph and the corresponding EDS spectrum of the Ti-Cu coated SS. The surface morphology of the treated sample had a graniform appearance composed of crystal grains and appeared as a fine, dense and compact structure (Fig, 4a). The surface of Ti-Cu coated SS was mainly composed of $\mathrm{Ti}$ and $\mathrm{Cu}$ with a nominal compositional ratio of 52.46: 47.54 (at. \%) as reflected in the EDS elemental spot scan of the coatings (Fig. 4b). As chemical composition is strongly influenced by the mode of magnetron sputtering, previous reports of $\mathrm{Ti}-\mathrm{Cu}$ films prepared by dc-MS and dual-MS mode achieved different stoichiometric $\mathrm{Ti}-\mathrm{Cu}$ ratios of 47:53 for dc-MS and 40:60 for the dual-MS technique [9]. 


\subsection{Antimicrobial activities of Ti-Cu coatings}

The antibacterial properties of Ti-Cu coated SS and untreated SS were evaluated by incubation with E.coli at $37{ }^{\circ} \mathrm{C}$ for 6 h (Fig. 5). The untreated SS was almost completely covered by bacterial colonies (Fig. 5a). However, few bacterial colonies presented on the surface of treated SS (Fig. 5b), indicating that the Ti-Cu coated SS inhibited bacterial colonization. The Ti-Cu coated SS exhibited powerful antimicrobial activity against $E$. coli.

Experimental results have shown that bacterial behavior on biomaterial surfaces depends on various factors, including surface morphology, surface roughness, surface hydrophilicity and the environment [24-26]. However, the dominant influential factor for killing of bacteria may changes in the chemical composition of biomaterial surfaces [23]. The antibacterial properties of Ti-Cu coated SS are dependent on the $\varepsilon$ - $\mathrm{Cu}$ phase because $\varepsilon$ - $\mathrm{Cu}$ precipitates enable $\mathrm{Cu}$-ions to be released from the surface of SS $[2,9]$.

Copper ions kill bacteria by destroying the cell wall and cell membrane, causing the cytoplasm to leak and oxidization of the cell's nucleus [27]. Relatedly, the antibacterial efficiency of all SSs can be as high as $99.99 \%$ when the $\mathrm{Cu}$ content exceeds 3.5 wt.\% [2], which is far less than in the Ti-Cu coated SS used in the present study at 54.60 wt. \%. This large amount of $\varepsilon-\mathrm{Cu}$ precipitated in the $\mathrm{Ti}-\mathrm{Cu}$ coatings corresponds to more $\mathrm{Cu}$-ions being dissolved on the surface of the SS, displaying greater antibacterial ability than lower amount of the antimicrobial $\mathrm{Cu}$ ion. Stranak et al. [9] verified $\mathrm{Ti}-\mathrm{Cu}$ films ( $\mathrm{Ti}: \mathrm{Cu}=9: 91$ at. \%) prepared using a dual 
High Power Impulse Magnetron Sputtering (dual-HiPIMS) technique demonstrating growth inhibition or killing effects against two staphylococcal species. Killing occurred during the first 24 to $96 \mathrm{~h}$, which indicates a high diffusion rate of copper species released into the cultivation medium. Zhang et al. [28] reported antibacterial rates against $E$. coli and $S$. aureus after the first polishing as $99.93 \%$ and $100 \%$ respectively, indicative of strong antibacterial properties of the Ti-Cu sample with a Ti:Cu ratio of 61.81 at. \%. On the other hand, Ti is highly reactive and has a higher affinity for oxygen than $\mathrm{Cu}$, where $\mathrm{TiO}_{2}$ typically forms spontaneously and instantly when fresh metal surfaces are exposed to air and/or moisture [29]. As $\mathrm{TiO}_{2}$ bactericidal activity starts its action by oxidative damage to the bacterial wall, a decrease in the interfacial energy of bacterial adhesive causes an increase in the chemical interaction between $E$. coli and the coatings, which is an additional factor that promotes bactericidal activity [30].

\subsection{Wettability and biological implications}

It is well known that the water contact angle on the surface of biomaterials is closely related to its bioactivity. A lower water contact angle usually corresponds to a higher surface bioactivity, which plays an important role in determining the histocompatibility of biomaterials. At present, we obtained water contact angles of the Ti-Cu coating and polished-AISI316L SS by means of a SL 200B contact angle measuring instrument. As observed in the water contact angle images (Fig. 6b), the Ti-Cu coated SS clearly had a lower contact angle $\left(18.4^{\circ} \pm 1.5^{\circ}\right)$ than that of polished-AISI316L SS $\left(55.8^{\circ} \pm 2.1^{\circ}\right)$ (Fig. 6a). Therefore the Ti-Cu coating has a better 
surface bioactivity than that of polished-AISI316L SS, displaying superior histocompatibility. In addition, the water contact angles reveal that Ti-Cu coatings are hydrophilic, implying that $\mathrm{Ti}-\mathrm{Cu}$ coated $\mathrm{SS}$ is suitable for bacterial adhesion, increasing the direct contact between bacteria and $\mathrm{Ti}-\mathrm{Cu}$ coatings, promoting an increase in bactericidal activity. These results are in agreement with Marciano et al. [30], where an increase in hydrophilic properties causes an increase in the interaction between $E$. coli and $\mathrm{TiO}_{2}$-DLC films, thus promoting bactericidal activity.

\subsection{Electrochemical corrosion properties}

Good corrosion resistance is one of the most important reasons for SS to be applied as orthopedic and dental implants. It is found that crevice and pitting corrosion occurs and ions $\left(\mathrm{Ni}^{2+}, \mathrm{Cr}^{3+}\right.$ and $\left.\mathrm{Cr}^{5+}\right)$ are released from SS in SBF, which results in degeneration of the properties of the material when implanted in the human body [31]. It is important to improve the corrosion resistance to prevent release of ions. With the aim of generating highly corrosion-resistant and infection resistant medical device surfaces, the corrosion properties of Ti-Cu coated SS316L were investigated in a SBF environment.

Fig. 7a reveals the potentiodynamic polarization curves of uncoated and coated SS316L samples in SBF solution at $37^{\circ} \mathrm{C}$. The polarization data are listed in Table 2. A higher corrosion potential was measured for the Ti-Cu coated SS samples than the uncoated SS316L $\left(E_{\text {corr }}=-0.431 \mathrm{~V}\right)$. This indicates that the coating is nobler than the substrate and that galvanic corrosion may occur between the coating and substrate, i.e., the substrate may be anodically corroded. 
The corrosion current density of each sample was calculated from the polarization curves using the Tafel extrapolation method [32], where lower $I_{\text {corr }}$ values were measured for the $\mathrm{Ti}-\mathrm{Cu}$ coated SS316L samples than the uncoated SS316L $\left(I_{\text {corr }}=8.53 \times 10^{-7} \mu \mathrm{A} / \mathrm{cm}^{2}\right)$. Generally, the corrosion current density is commonly cited as an important criterion to evaluate the kinetics of corrosion processes. The low corrosion current density of the $\mathrm{Ti}-\mathrm{Cu}$ coating confirmed the improvement in corrosion resistance of the SS substrate. Since the corrosion rate of a tested sample is normally proportional to its corrosion current density, the Ti-Cu coating had a lower calculated corrosion rate than uncoated SS based on the potentiodynamic polarization tests.

Fig. $7 \mathrm{~b}$ displays the Nyquist plots of the uncoated and coated SS 316L samples immersed in SBF electrolyte. The Ti-Cu coated SS316L had higher impedance than the uncoated SS316L, increasing the immersion time. This behavior represents an improvement in the corrosion resistance of the materials due to the formation of stable compounds that blocks the electrolyte from penetrating into the coatings. The impedance tends to increase with immersion time, revealing the protective behavior induced by the formation of protective layers that block the passage of electrolytes, in agreement with their lower passive current determined by potentiodynamic tests.

Fig. 8 shows the SEM micrographs of the eroded surface of the Ti-Cu coated SS and uncoated SS substrate after corrosion testing in Hanks' solution. The surface of uncoated SS316L was severely eroded in SBF, displaying deep holes (Fig. 8a and b) representative of pitting corrosion. As reported elsewhere for SS materials [33-35], 
pitting is more likely to initiate from inclusions and also from the interface between the inclusion and metal. Therefore, the pitting of SS316L was likely initiated from the surface groove or from the interface between the precipitates and inclusions, which were the weakest points on the surface (Fig. 8a and b).

Compared with uncoated SS, localized pits were clearly visible on the surface of the Ti-Cu coatings (Fig. 8c and d). The pits may be initiated from intermetallic inclusions and may also be the result of local dissolution at the coated SS surface. Because the oxide thickness on the surface is not homogenous the thinner oxide regions are more susceptible to pitting corrosion.

Based on the SEM micrographs (Fig. 8), it can be concluded that the Ti-Cu coatings deposited by CFUBMS showed much better corrosion resistance than uncoated SS, which can easily be justified by two lines of argument. Firstly, the corrosion resistance of the Ti-Cu coated SS was ascribed to the $\mathrm{Cu}_{2} \mathrm{O}$ passive layer which maintains high resistance by preventing doping by $\mathrm{Cl}^{-}$ions [36]. Secondly, the corrosion resistance of the Ti-Cu coated SS relies on the formation of a very stable and protective oxide film on its surface. As $\mathrm{Ti}$ is highly reactive and has a higher affinity for oxygen than $\mathrm{Ni}$, the beneficial surface oxide film, normally $\mathrm{TiO}_{2}$, forms spontaneously when fresh metal surfaces are exposed to air and/or moisture [37].

\subsection{Corrosion-wear behavior of coatings}

The low hardness and poor wear resistance of SSs are another major concern to potential users. Therefore, the wear resistance of the surface modified layer must also be considered in addition to the bactericidal ability. Together these can determine 
whether a surface modification is merely a contaminant or is able to prevent bacterial growth. Therefore, the friction and wear behaviors of SS substrates and Ti-Cu coated SS were measured using a ball-on-disc type tribometer under sliding against $\mathrm{Si}_{3} \mathrm{~N}_{4}$ counterparts under boundary lubricated conditions with SBF. Fig. 9 illuminates the dynamic coefficient of frictions (cofs) of the uncoated and coated samples during the tests. Fig. 10 is the SEM micrographs of the wear tracks after sliding tests under boundary lubricated conditions with Hanks' solution. Furthermore, the elemental concentrations in typical zones on the worn samples were characterized using EDS to provide supplementary information to better elucidate the deterioration mechanisms (Fig. 11). The cof curve (Fig. 9) of uncoated SS316L presented a slip-stick behavior and the average cof of the SS316L under the SBF lubrication was about 0.69 , with the cof curve severely fluctuating (up and down range was \pm 0.13 ). This is because that more corrosion likely occurred at the SS surface with SBF resulting in the corrosion products accelerating the wear of the counterface ball and SS316L in SBF. On the wear track of the uncoated SS316L after the wear test with SBF (Fig. 10a), the worn surface of the SS showed signs of abrasive and adhesion wear as well as severe plastic deformation on the edges of the wear scar, indicating that the SS substrate experienced adhesion wear, abrasive wear, and severe plastic deformation when sliding against the $\mathrm{Si}_{3} \mathrm{~N}_{4}$ ball. EDS analysis in Fig. 11(a) shows the presence of $\mathrm{O}$ in zone 1 and 2 which indicates oxidation has taken place due to the ability of the metal to oxidize under ambient conditions. The pull-off adhesion and oxidation product were crushed to fine irregular shaped particles that could create abrasive wear [38-40]. 
Thereby, the dominating wear mechanism of SS was adhesive wear, which was associated with oxidation wear and abrasive wear.

The average cofs for Ti-Cu coated SS 316L under boundary lubricated conditions with Hanks' solution were extrapolated from the dynamics curves as 0.63 (Fig. 9). The width of wear scars on Ti-Cu coatings was wider than that of SS (Fig. 10b). For the Ti-Cu coated SS (Fig. 10(b)), the contents of $\mathrm{Ti}$ and $\mathrm{Cu}$ are found on both points 1 and 2 . This confirmed that the Ti-Cu coatings had not been worn through. Elements of $\mathrm{Si}$, $\mathrm{Ti}$ and $\mathrm{O}$ were detected at point 1, indicative of abrasive wear and oxidative wear mechanism. Three reasons can be called upon for this. First, it has been reported that the $\mathrm{Si}_{3} \mathrm{~N}_{4}$ ball tribochemical reaction (oxidation) forms a thin $\mathrm{SiO}_{2}$ film under the friction heat and applied load during sliding [41]. This $\mathrm{SiO}_{2}$ film has a positive effect on the coefficient of friction and wear resistance of the friction pair [42]. Thus, the low chemical affinity of the Ti-Cu coatings for $\mathrm{Si}_{3} \mathrm{~N}_{4}$ and the protective $\mathrm{SiO}_{2}$ film formed on the counterpart resulted in the favorable anti-adhesion properties of the Ti-Cu coated SS. Second, the anticorrosion-wear protection performance of $\mathrm{Ti}-\mathrm{Cu}$ coatings was due to the formation of a Ti-O passive layer on the coating surface. $\mathrm{TiO}_{2}$ has been employed as protective coatings to $\mathrm{SS}$ as $\mathrm{TiO}_{2}$ possesses low friction, good wear resistance, good corrosion resistance and good biocompatibility $[43,44]$. Third, the presence of $\mathrm{Cu}$ in the Ti-Cu alloyed layer as a solid lubricant in reducing friction can reduce adhesive wear. By this means, the wear resistance of 316LSS coated with Ti-Cu is obviously improved. EDS analysis of point 2 in Fig. 11(b) indicated the presence of oxidation. The cof curves and SEM 
morphology observations indicated that the Ti-Cu coatings were relatively stable in SBF and that effect of the body fluid solution on the tribological properties was trivial. Considering the influence of tribochemical reactions with $\mathrm{Si}_{3} \mathrm{~N}_{4}$, the main wear mechanism of Ti-Cu coatings was abrasive wear.

It was clearly notable that the wear rate of the Ti-Cu coated SS $\left(1.97 \times 10^{-4} \mathrm{~mm}^{3} /\right.$ $(\mathrm{N} \cdot \mathrm{m}))$ was lower than uncoated SS $\left(4.54 \times 10^{-4} \mathrm{~mm}^{3} /(\mathrm{N} \cdot \mathrm{m})\right)$ when comparing the sliding wear rate of the uncoated and coated samples after sliding tests in SBF (Fig. 12). The Ti-Cu coated samples had much smaller wear rates than the uncoated SS, indicating the coated SS has superior wear resistance than the uncoated SS, likely attributable to an enhancement in surface hardness of the coatings [45, 46].

Figure 13 shows 2D non-contact surface mapping across the wear scars of the uncoated and coated samples after sliding tests in SBF. Ti-Cu coated SS had a smaller wear scar width and depth than the uncoated SS. In SBF, the wear scar depth of Ti-Cu coated SS was about $1.54 \mu \mathrm{m}$, which was much smaller than that of the SS under the same wear condition, where the wear scar depth of the SS is much larger than $4.20 \mu \mathrm{m}$. Moreover, one peak with a height of about $1.31 \mu \mathrm{m}$ appeared on the edge of the wear scar of the uncoated SS, corresponding to severe plastic deformation of the SS (see Fig. 11a).

In summary, the ideal antibacterial SS surfaces for application should have excellent antibacterial properties and adequate antibacterial durability. The above results demonstrate that the $\mathrm{Ti}-\mathrm{Cu}$ coated surface exhibits excellent antibacterial properties on Gram-negative E. coli. The thickness of the alloyed layer is about 1.5 
$\mu \mathrm{m}$. The coated layer also improves the wear and corrosion resistance, hence it is expected that the Ti-Cu coated SS will have durable antibacterial function for various SS applications. Future work will include testing the biocompatibility of this Ti-Cu coated SS and its fatigue properties in biological environments.

\section{Conclusions}

In summary, an antibacterial surface combined with adequate surface corrosion and wear resistance has been successfully prepared using the Closed Field Unbalanced Magnetron Sputtering (CFUBMS) system. The coatings are uniform, continuous and compact, with a total coating thickness of $\sim 1.5 \mu \mathrm{m}$. The coatings mainly consisted of $\mathrm{Cu}_{4} \mathrm{Ti}_{3}, \mathrm{Cu}_{0.81} \mathrm{Ni}_{0.19}, \mathrm{TiNi}_{0.8} \mathrm{Cu}_{0.2}$ and $\gamma$-Fe. Antibacterial activity was greatly improved, with nearly all bacteria overlaid on Ti-Cu coated AISI316L SS being killed within $6 \mathrm{~h}$. An improvement in both the wear resistance and the corrosion-resistant capacities of Ti-Cu coated surfaces over uncoated SS was also achieved. Thus a duplex surface system that combines bacterial inhibition and corrosion-wear resistance properties might provide long-term antibacterial functions for biomedical surfaces.

\section{Acknowledgments}

The authors would like to thank the financial support from National Natural Science Foundation of China (51171125), National Natural Science Foundation of China (11172195), National Science Foundation for Distinguished Young Scholars of China (E010101), Shanxi Province Programs for Science and Technology Innovation (2014jyt03), Post-doctoral Science Fund of China (2013M541209), Youth Foundation 
of Taiyuan University of Technology (2012L073), Program for the Young Teams of Taiyuan University of Technology (2013T065), Natural Science Foundation for Young Scientists of Shanxi Province (2013021013-5) and Shanxi province Nature Science Fund (2012011021-3).

\section{References}

[1] K. Yang, M.Q. LÜ, J. Mater. Sci. Technol. 23 (2007) 333-336.

[2] I.T. Hong, C.H. Koo, Mater. Sci. Eng., A 393 (2005) 213-222.

[3] J. Macák, P. Sajdl, P. Kučera, R. Novotný, J. Vošta, Electrochim. Acta 51 (2006) $3566-3577$.

[4] Y.F. Liu, J.S. Mu, X.Y. Xu, S.Z. Yang, Mater. Sci. Eng., A 458 (2007) 366-370.

[5] J. Zhao, H.J. Feng, H.Q. Tang, J.H. Zheng, Surf. Coat. Technol. 201 (2007) $5676-5679$.

[6] W. Zhang, Y.H. Zhang, J.H. Ji, J. Zhao, Q. Yan, P.K. Chu, Polymer 47 (2006) $7441-7445$.

[7] A. Daniel, C. Le Pen, C. Archambeau, F. Reniers, Appl. Surf. Sci. 256 (2009) S82-S85.

[8] Y.Z. Wan, S. Raman, F. He, Y. Huang, Vacuum 81 (2007) 1114-1118.

[9] V. Stranak, H. Wulff, H. Rebl, C. Zietz, K. Arndt, R. Bogdanowicz, B. Nebe, R. Bader, A. Podbielski, Z. Hubicka, R. Hippler, Mater. Sci. Eng., C 31 (2011) 1512-1519.

[10] V. Stranak, H. Wulff, R. Bogdanowicz, S. Drache, Z. Hubicka, M. Cada, M. Tichy, R. Hippler, Eur. Phys. J. D 64 (2011) 427-435. 
[11] N. Vershinin, K, Filonov, B. Straumal, W. Gust, R. Dimitriou, A. Kovalev, J. Camacho, Surf. Coat. Technol. 125 (2000) 223-228.

[12] M. Bosetti, A. Massè, E. Tobin, M. Cannas, Biomaterials 23 (2002) 887-892.

[13] P. Xu, C.X. Lin, C.Y. Zhou, X.P. Yi, Surf. Coat. Technol. 238 (2014) 9-14.

[14] Y.Q. Liu, J.B. Li, E.E. Oguzie, Y. Li, D. Chen, K. Yang. F.H. Wang, Corros. Sci. 51 (2009) 1083-1086.

[15] K.F. Huo, X.M. Zhang, H.R. Wang, L.Z. Zhao. X.Y. Liu, P.K. Chu, Biomaterials 34 (2013) 3467-3478.

[16] H.L. Huang, Y.Y. Chang, M.C. Lai, C.R. Lin, C.H. Lai, T.M. Shieh, Surf. Coat. Technol. 205 (2010) 1636-1641.

[17] G. Grass, C. Rensing, M. Solioz, Appl. Environ. Microbiol. 77 (2011) 1541-1547.

[18] F. Heidenau, W. Mittelmeier, R. Detsch, M. Haenle, F. Stenzel, G. Ziegler, H.A. Gollwitzer, J. Mater. Sci. Mater. Med. 16 (2005) 883-888.

[19] A. Tekin, J.W. Martin, B.A. Senior, J. Mater. Sci. 26 (1991) 2458-2466.

[20] J.H. Park, J.K. Kim, B.H. Lee, S.S. Kim, K.Y. Kim, Scripta Mater. 68 (2013) 237-240.

[21] J.K. Kim, Y.H. Kim, J.S. Lee, K.Y. Kim, Corros. Sci. 52 (2010) 1847-1852.

[22] K. Feng, X. Cai, Z.G. Li, P.K. Chu, Mater. Lett. 68 (2012) 450-452.

[23] X.Y. Zhang, Y. Ma, N.M. Lin, X.B. Huang, R.Q. Hang, A.L. Fan, B. Tang. Surf. Coat. Technol. 232 (2013) 515-520.

[24] Y. Dong, X. Li, L. Tian, T. Bell, R.L. Sammons, H. Dong. Acta Biomater. 7 (2011) 447-457. 
[25] W. Zhang, Y.J. Luo, H.Y. Wang, J. Jiang, S.H. Pu, P.K. Chu, Acta Biomater. 4 (2008) 2028-2036.

[26] B.S. Necula, L.E. Fratila-Apachitei, S.A.J. Zaat, I. Apachitei, J. Duszczyk, Acta Biomater. 5 (2009) 3573-3580.

[27] N. Ookubo, S. Nakamura, M. Yamamoto, K. Miyakuso, M. Hasagawa. Nisshin Steel 77 (1998) 69-78. (in Japanese)

[28] E.L. Zhang, F.B. Li, H.Y. Wang, J. Liu, C.M. Wang, M.Q. Li, K. Yang, Mater. Sci. Eng., C 33 (2013) 4280-4287.

[29] L. Tan, R.A. Dodd, W.C. Crone, Biomaterials 24 (2003) 3931-3939.

[30] F.R. Marciano, D.A. Lima-Oliveira, N.S. Da-Silva, A.V. Diniz, E.J. Corat, V.J. Trava-Airoldi, J. Colloid Interface Sci. 340 (2009) 87-92.

[31] M. Finšgar, S. Fassbender, S. Hirth, I. Milošev, Mater. Chem. Phys. 116 (2009) 198-206.

[32] H.Y. Yang, X.W. Guo, G.H. Wu, S.H. Wang, W.J. Ding, Surf. Coat. Technol. 205 (2011) 2907-2913.

[33] N. Ebrahimi, M.H. Moayed, A. Davoodi, Corros. Sci. 53 (2011) 1278-1287.

[34] N.Ebrahimi, M. Momeni, M.H. Moayed, A. Davoodi, Corros. Sci. 53 (2011) 637-644.

[35] F. Eghbali, M.H. Moayed, A. Davoodi, N. Ebrahimi, Corros. Sci. 53 (2011) $513-522$.

[36] A.D. Modestov, G.D. Zhou, Y. P. Wu, T. Notoya, D.P. Schweinsberg, Corros. Sci. 36 (1994) 1931-1946. 
[37] L. Tan, R.A. Dodd, W.C. Crone, Biomaterials 24 (2003) 3931-3939.

[38] X.H. Zhang, D.X. Liu, H.B. Tan, X.F. Wang, Surf. Coat. Technol. 203 (2009) 2315-2321.

[39] I. Haq, T.I. Khan, Surf. Coat. Technol. 205 (2011) 2871-2875.

[40] N.F. Garza-Montes-de-Oca, W.M. Rainforth, Wear 267 (2009) 441-448

[41] B. Basu, J. Vleugels, O. Van Der Biest, Wear 250 (2001) 631-641.

[42] A.K. Keshri, A. Agarwal, J. Therm. Spray Techn. 20 (2011) 1217-1230.

[43] D. Siva Rama Krishna, Y. Sun, applied surface science 252 (2005) 1107-1116.

[44] M.C. Garcia-Alonso, L. Saldana, G. Valles, J.L. Gonzalez-Carrasco, J. Gonzalez-Cabrero, M.E. Martinez, E. Gil-Garay, L. Munuera, Biomaterials 24 (2003) 19-26.

[45] Y. Chen, X.Y. Nie, Surf. Coat. Technol. 206 (2011) 1977-1982.

[46] M. Li, J. Huang, Y.Y. Zhu, Z.G. Li, Surf. Coat. Technol. 206 (2012) 4021-4026.

Table captions

Table 1 Chemical composition of the Hanks' solution.

Table 2 Potentiodynamic polarization results of the corrosion in simulated body fluid.

Figure captions

Figure 1 Schematic diagram of sliding friction and wear testing apparatus.

Figure 2 XRD patterns of Ti-Cu coated SS.

Figure 3 Component distribution of Ti-Cu coated SS.

Figure 4 SEM image (a) and corresponding EDS spectrum (b) of Ti-Cu coated SS. 
Figure 5 Antimicrobial effects of (a) the untreated and (b) treated AISI316L SS against E. coli.

Figure 6 The images of water contact angles of (a) uncoated and (b) Ti-Cu coated SS. Figure 7 Potentiodynamic polarization curves (a) and Nyqusit plots (b) of uncoated and coated SS in the SBF at $37^{\circ} \mathrm{C}$.

Figure 8 (a-d) are SEM micrographs of surfaces on $(a, b)$ uncoated SS and $(c, d)$ Ti-Cu coated SS after polarization tests, respectively and (b, d) are the corresponding magnified images of $(a, c)$.

Figure 9 Dynamic COF curves of uncoated and Ti-Cu coated SS against $\mathrm{Si}_{3} \mathrm{~N}_{4}$ balls with SBF.

Figure 10 SEM micrographs of wear tracks on (a) uncoated and (b) Ti-Cu coated SS after sliding wear tests with SBF.

Figure 11 EDS spectrum of worn surfaces on (a) uncoated and (b) Ti-Cu coated SS after sliding wear tests with SBF.

Figure 12 Wear rates of tested samples after sliding against $\mathrm{Si}_{3} \mathrm{~N}_{4}$.

Figure 13 Wear scars of tested samples after sliding against $\mathrm{Si}_{3} \mathrm{~N}_{4}$. 


\begin{tabular}{cc}
\hline Components & Concentration $(\mathrm{g} / \mathrm{l})$ \\
\hline $\mathrm{NaCl}$ & 8.0 \\
$\mathrm{CaCl}$ & 0.14 \\
$\mathrm{KCl}$ & 0.40 \\
$\mathrm{NaHCO}_{3}$ & 0.35 \\
$\mathrm{Glucouse}_{2}$ & 1.0 \\
$\mathrm{MgCl}_{2} \cdot 6 \mathrm{H}_{2} \mathrm{O}$ & 0.10 \\
$\mathrm{Na}_{2} \mathrm{HPO}_{4} \cdot 2 \mathrm{H}_{2} \mathrm{O}$ & 0.06 \\
$\mathrm{KH}_{2} \mathrm{PO}_{4}$ & 0.06 \\
$\mathrm{MgSO}_{4} \cdot 7 \mathrm{H}_{2} \mathrm{O}$ & 0.06 \\
\hline
\end{tabular}




\begin{tabular}{ccc}
\hline Samples & $E_{\text {corr }}(\mathrm{V})$ & $I_{\text {corr }}\left(\mathrm{A} \cdot \mathrm{cm}^{-2}\right)$ \\
\hline SS & -0.431 & $8.53 \times 10^{-7}$ \\
Ti-Cu coated SS & -0.088 & $7.33 \times 10^{-8}$ \\
\hline
\end{tabular}




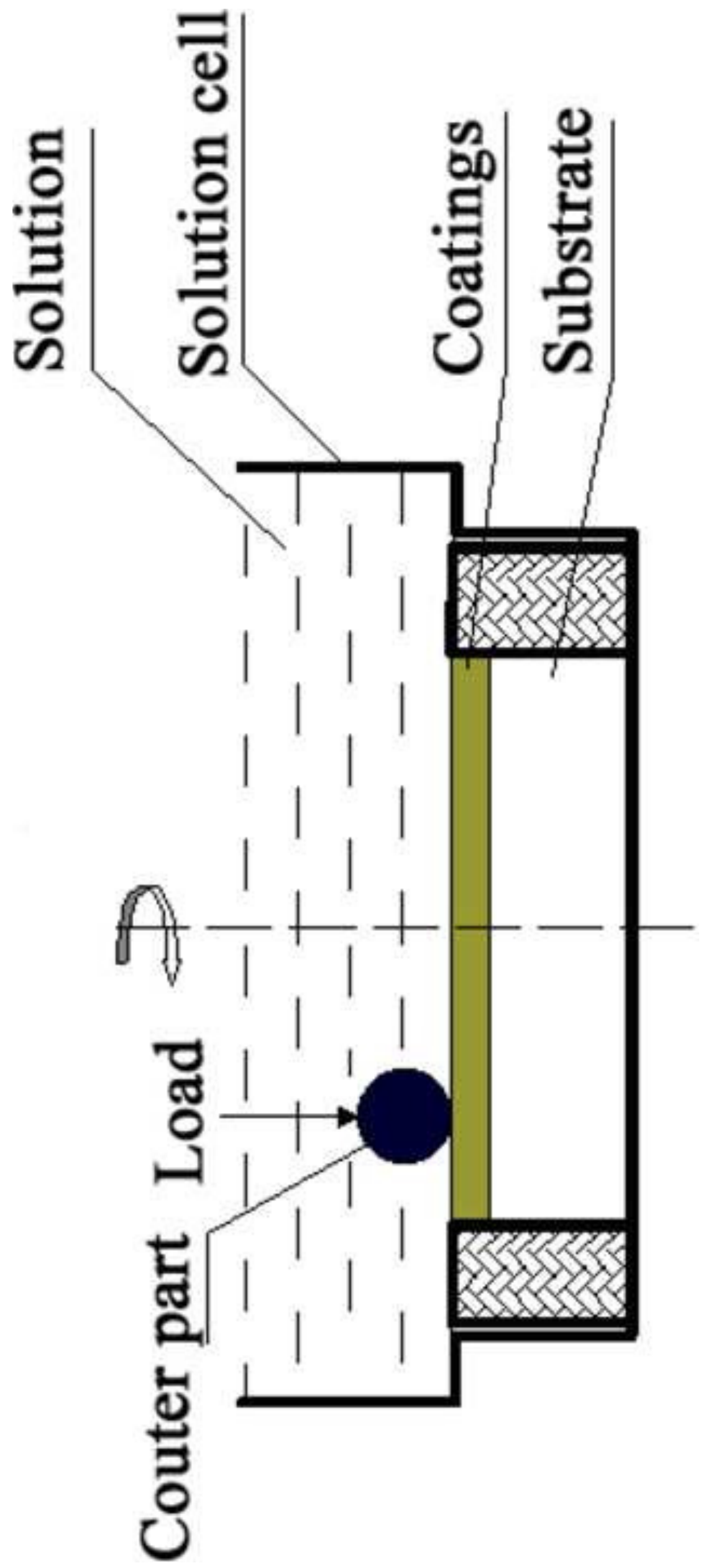




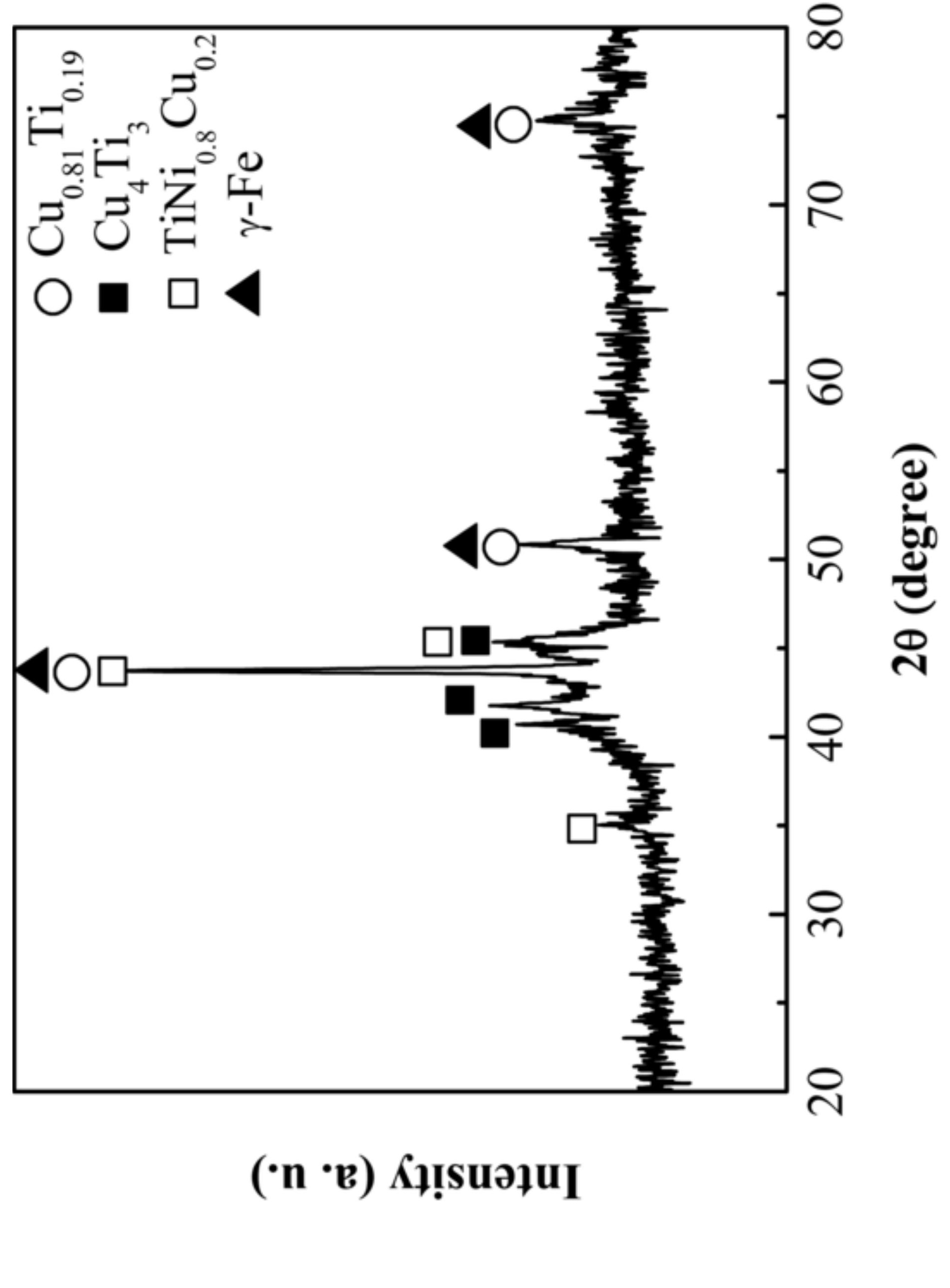




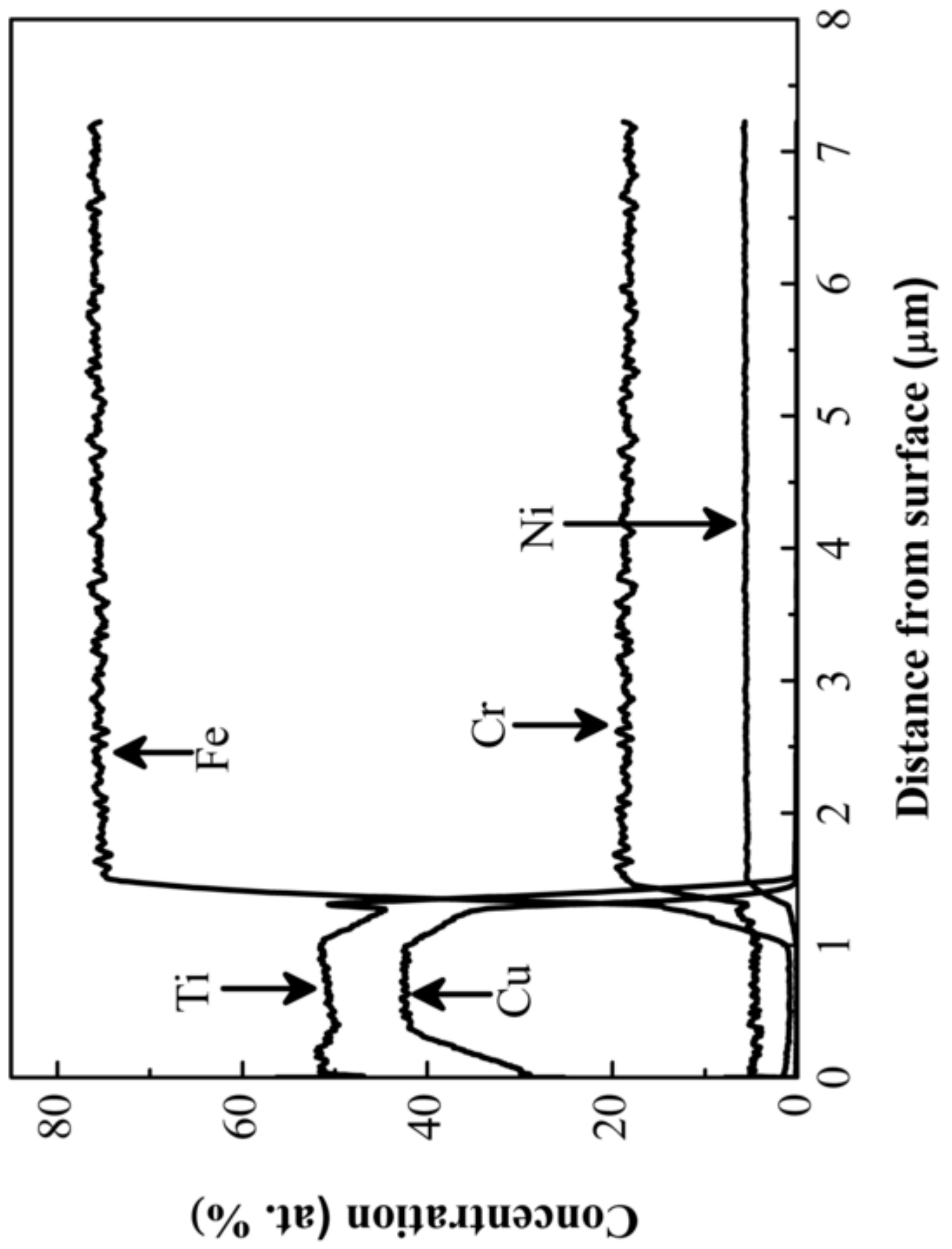



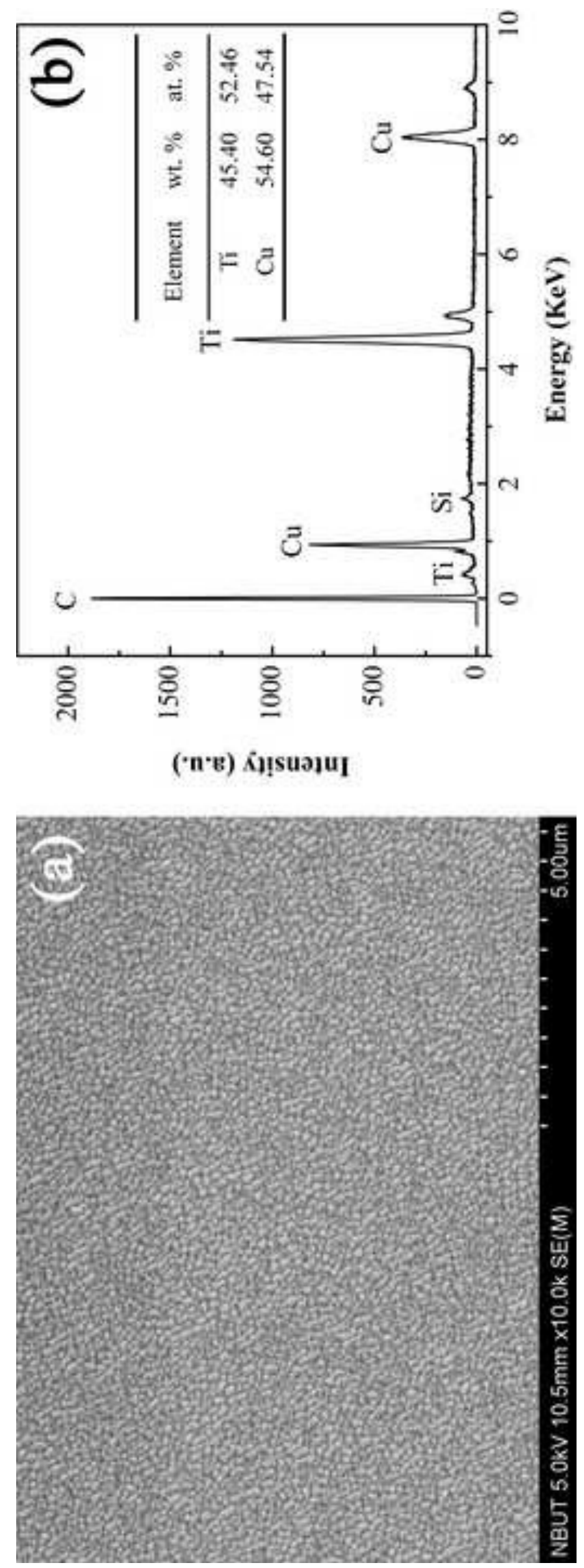

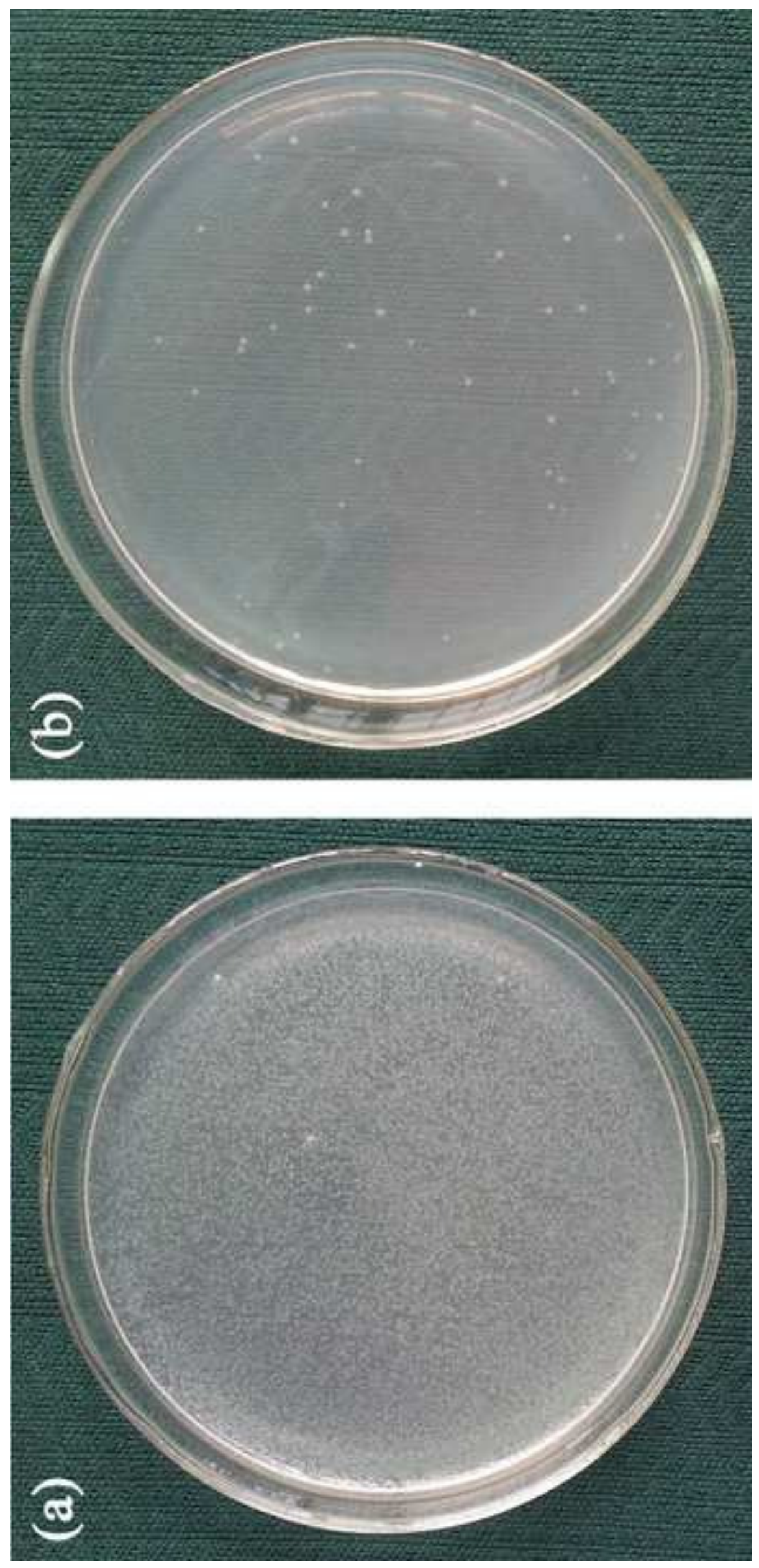

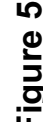




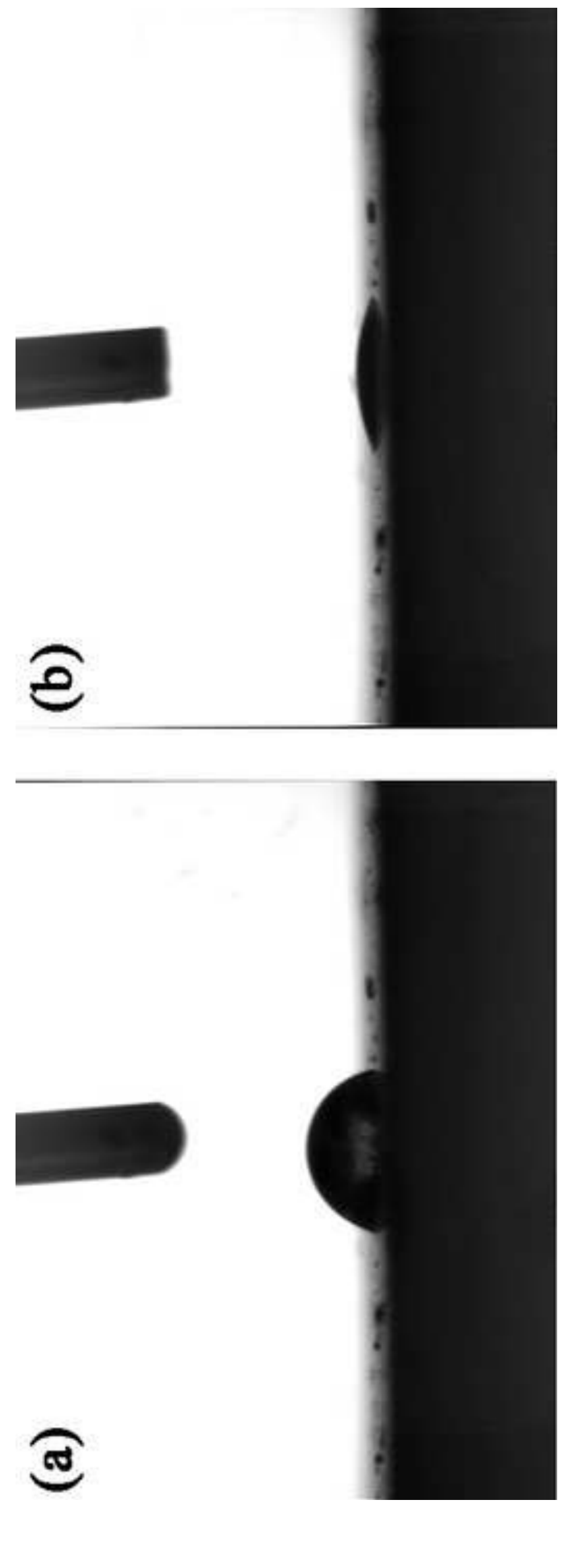



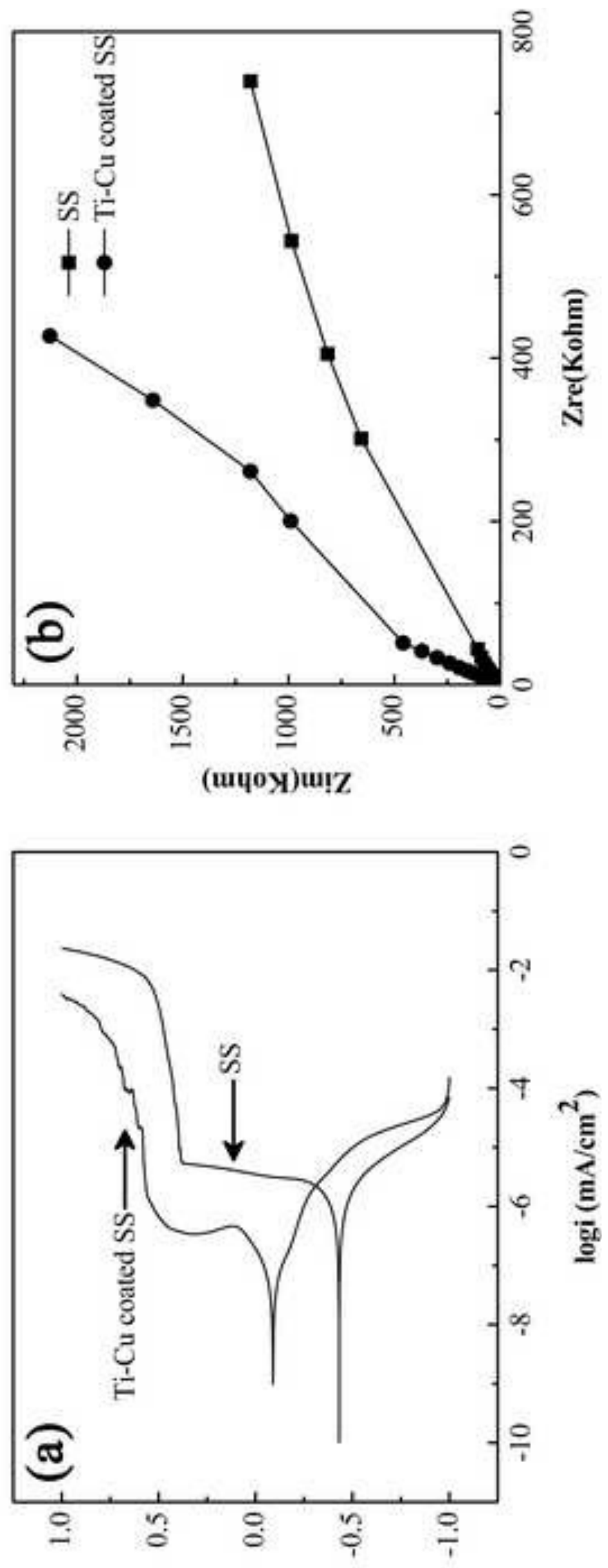

(A) 3 

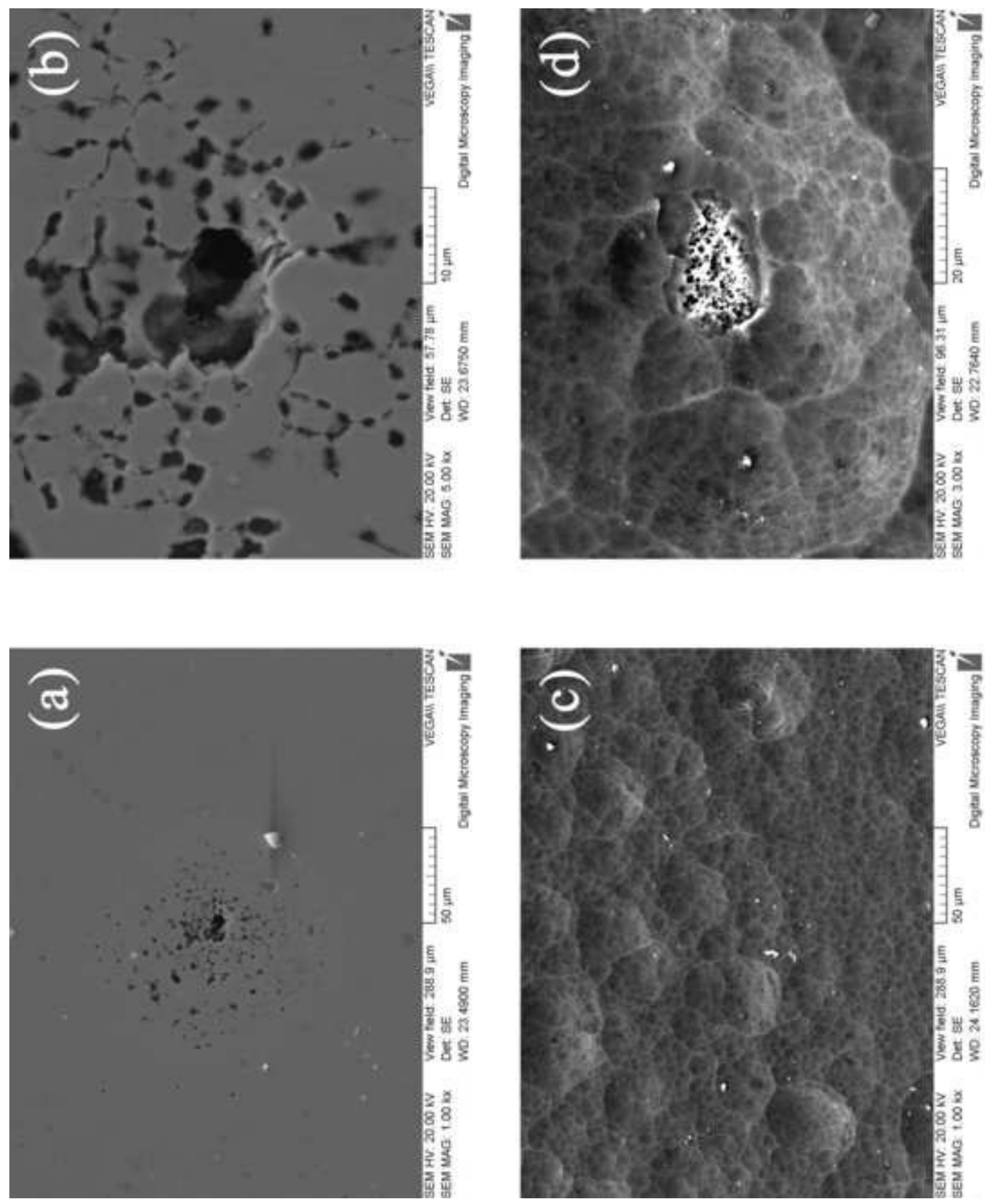

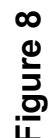




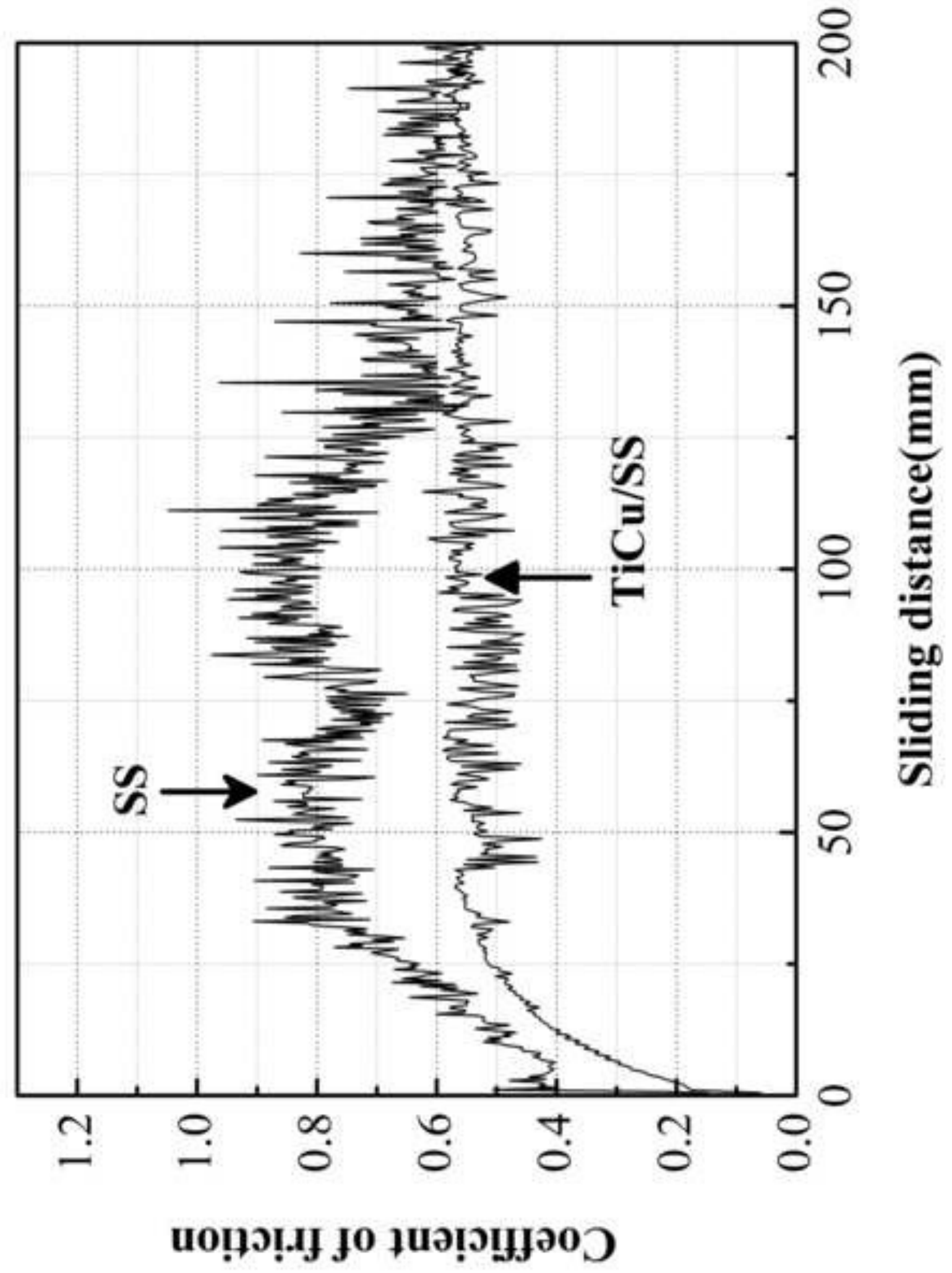



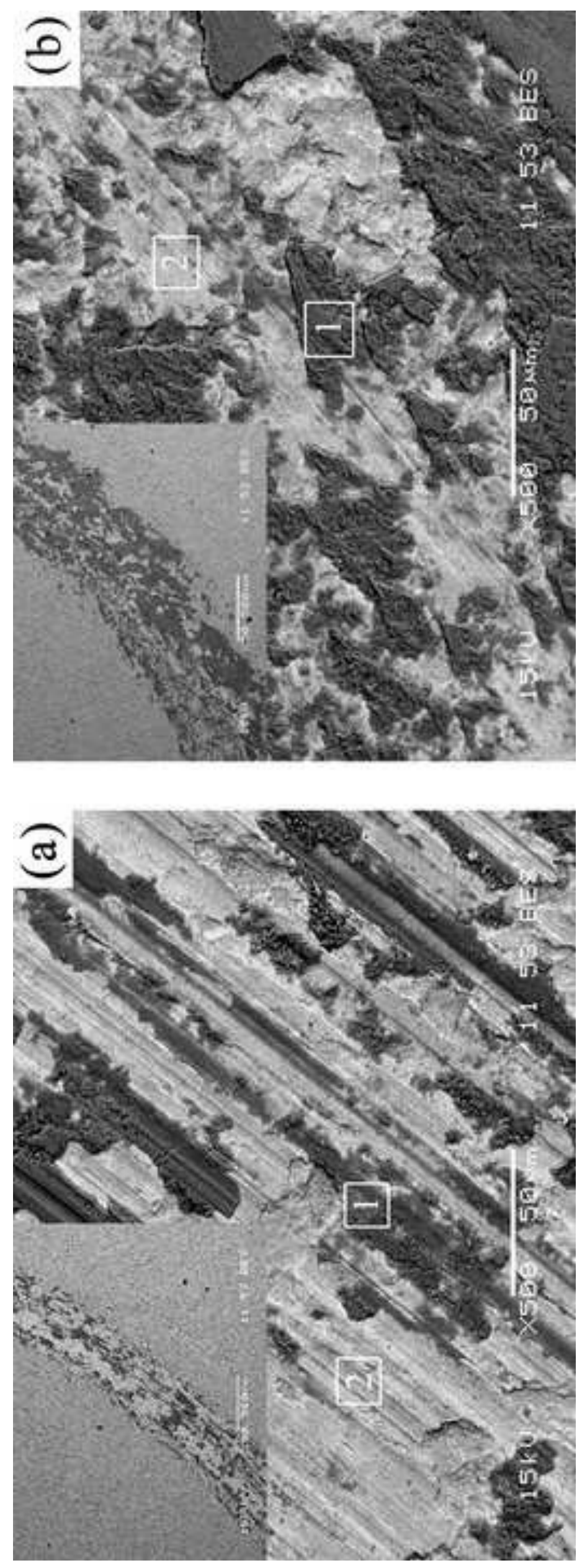


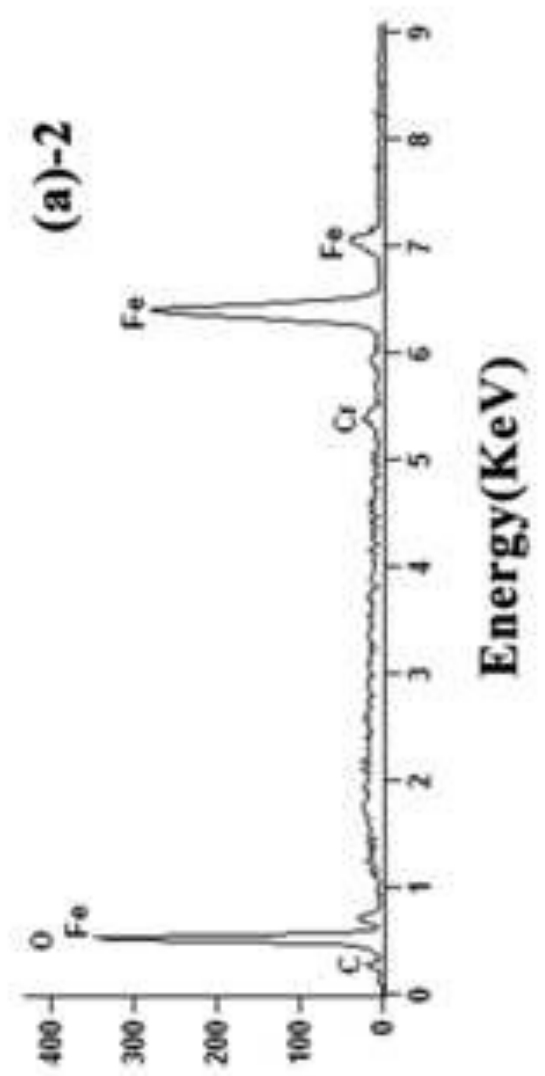

\section{$(\cdot n \cdot \boldsymbol{\varepsilon}) \mathbf{K} ! !$ suวฺุuI}

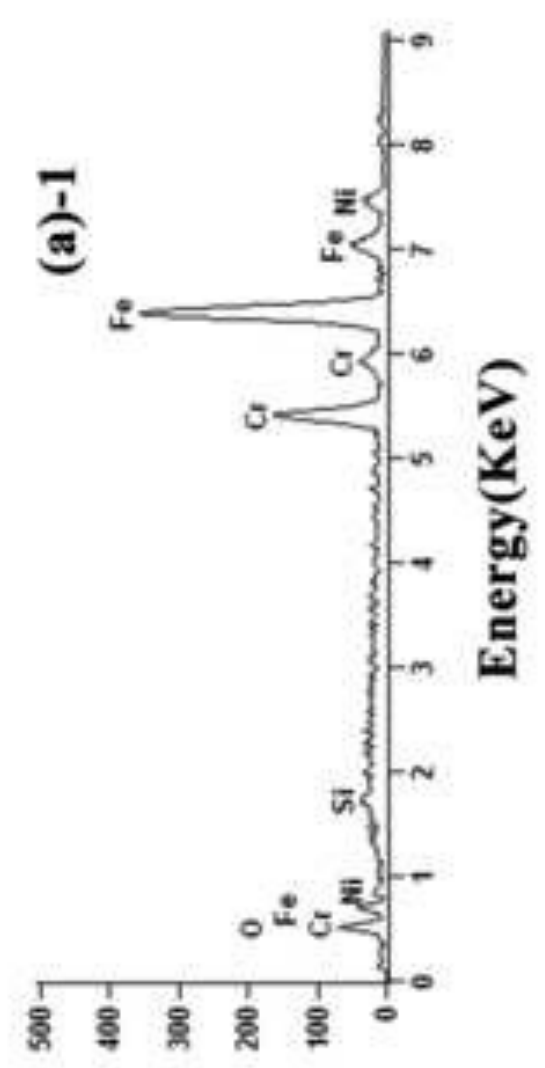

('n'ह) K!!

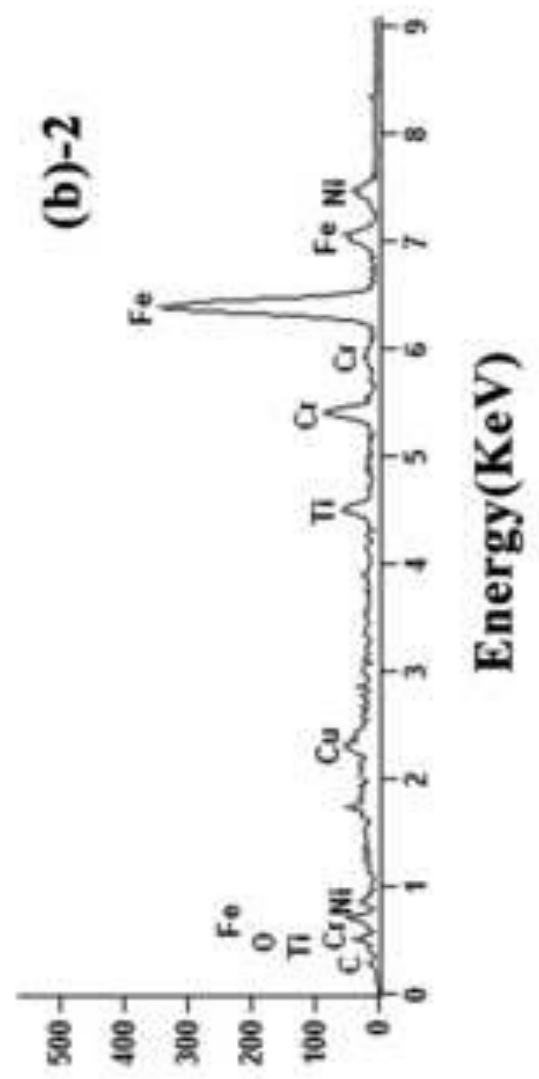

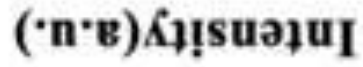

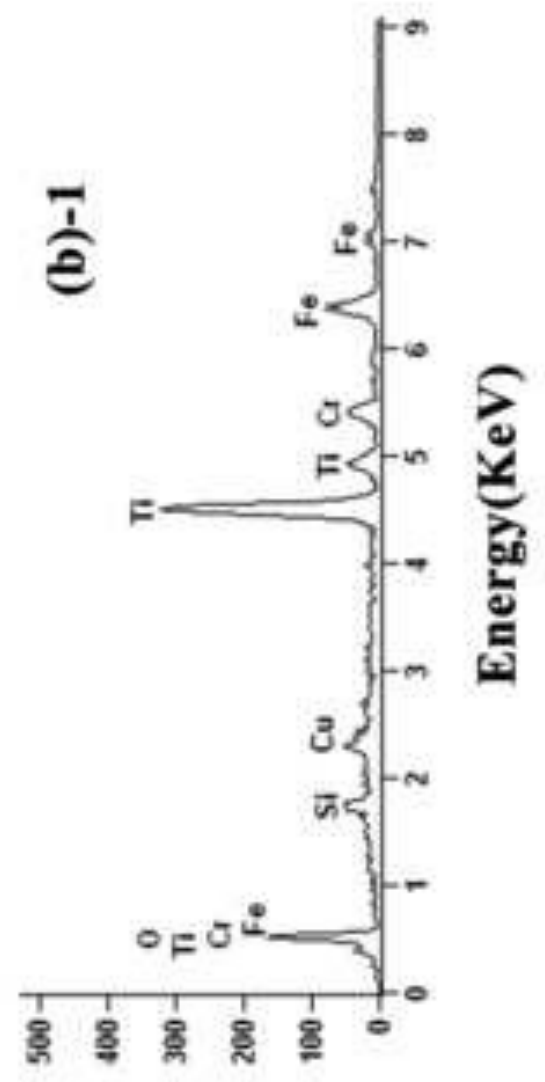

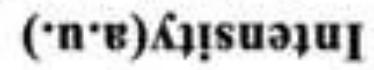




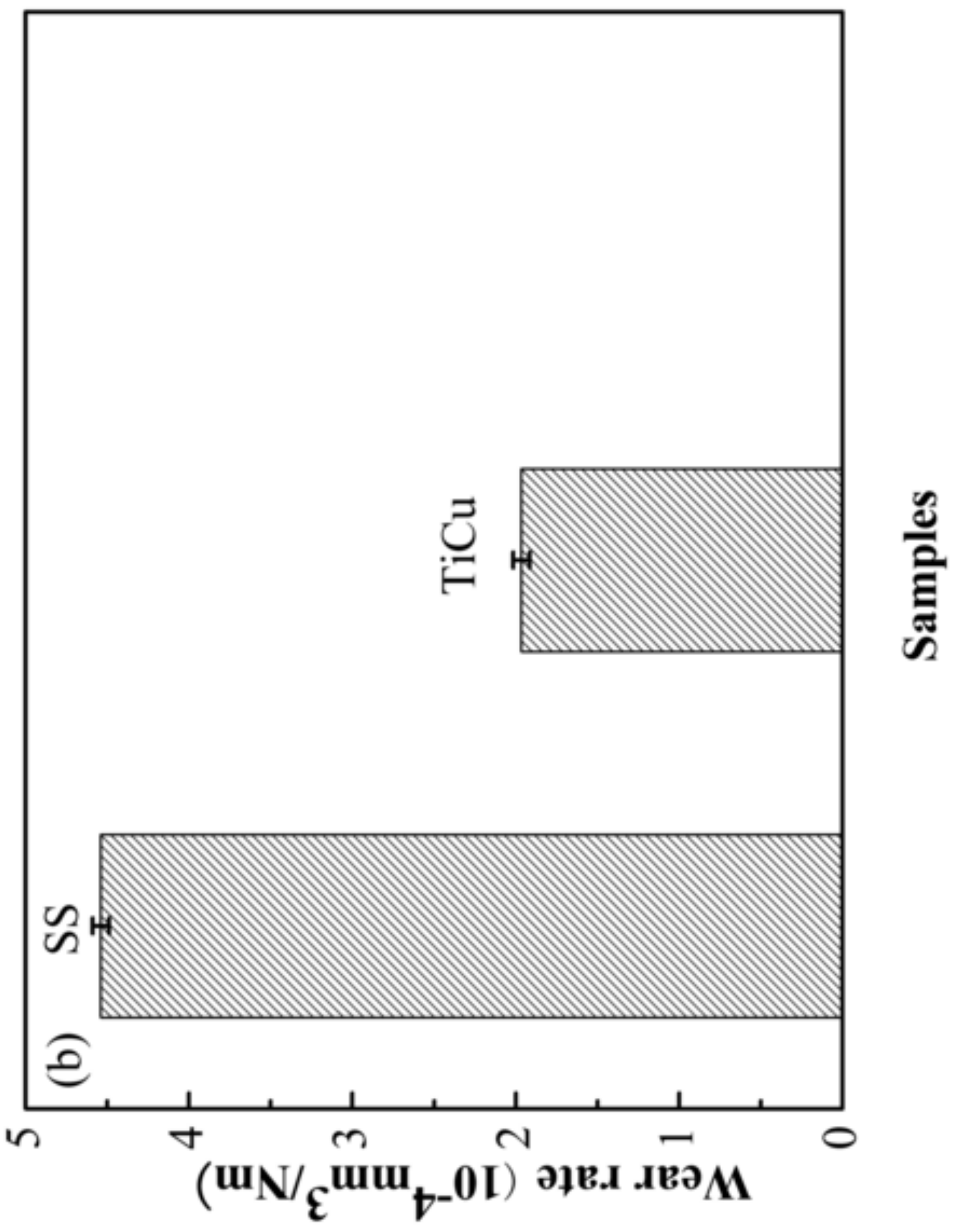




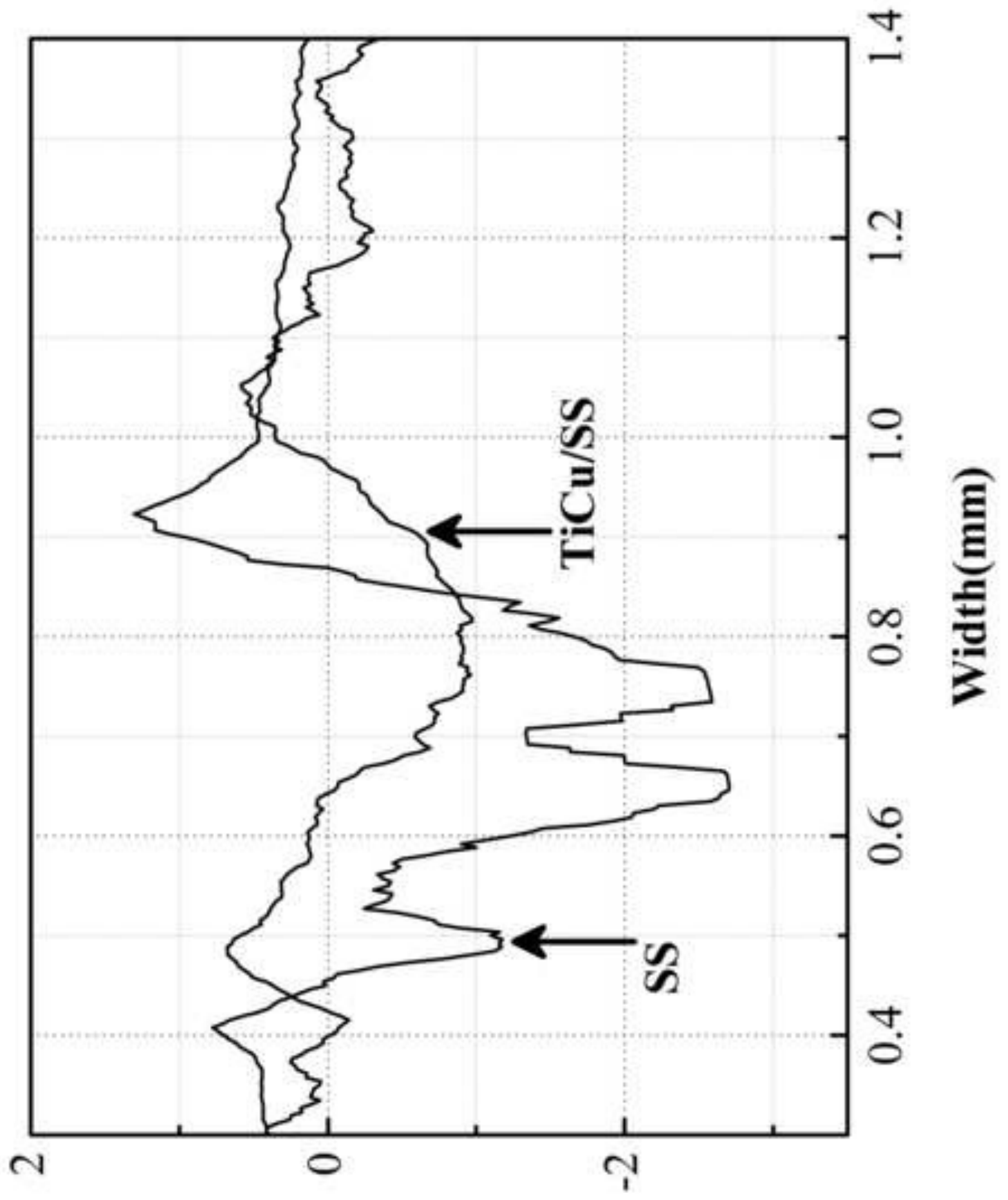

(uri) प1dәव 